\title{
Crystal structure of $\kappa-\mathrm{In}_{2} \mathrm{Se}_{3}$
}

\author{
J. Jasinski ${ }^{\text {a) }}$, W. Swider, J. Washburn and Z. Liliental-Weber \\ Lawrence Berkeley National Laboratory, Berkeley, CA 94720 \\ A. Chaiken, K. Nauka, G.A. Gibson and C.C. Yang \\ Hewlett Packard, Palo Alto, CA 94304
}

Structural properties of single-phase films of $\kappa-\mathrm{In}_{2} \mathrm{Se}_{3}$ and $\gamma-\mathrm{In}_{2} \mathrm{Se}_{3}$ were investigated. Both films were polycrystalline but their microstructure differed considerably. The alattice parameter of $\kappa-\operatorname{In}_{2} \mathrm{Se}_{3}$ has been measured. Comparison between these two materials indicates that $\kappa-\mathrm{In}_{2} \mathrm{Se}_{3}$ has a significantly larger unit cell $(\Delta \mathrm{c}=2.5 \pm 0.2 \%$ and $\Delta \mathrm{a}=13.5 \pm 0.5 \%$ ) and a structure more similar to the $\alpha$-phase of $\operatorname{In}_{2} \mathrm{Se}_{3}$.

\footnotetext{
a) E-mail: jbjasinski@lbl.gov
} 
Due to its potential application in photovoltaic devices $\operatorname{In}_{2} \mathrm{Se}_{3}$ is one of the most extensively studied binary chalcogenide alloys of the type III-VI. There are four relatively well-known phases of this compound $(\alpha, \beta, \gamma, \delta)$ and recently a new $\kappa$ phase of $\mathrm{In}_{2} \mathrm{Se}_{3}$ has been discovered.[1] Still little is known about its properties. Many of the studies performed on $\mathrm{In}_{2} \mathrm{Se}_{3}$ have been done on multiphase films, thus preventing a full understanding of its chemical and physical properties. This paper reports structural data obtained on single-phase films of $\kappa$ and $\gamma$ phases of $\operatorname{In}_{2} \mathrm{Se}_{3}$. From comparison of these results crystallographic parameters of the $\kappa-\mathrm{In}_{2} \mathrm{Se}_{3}$ were determined.

Evaporation from elemental sources via Knudsen cells was used to deposit thin films of $\mathrm{In}_{2} \mathrm{Se}_{3}$ on $\mathrm{Si}$ or $\mathrm{Si} / \mathrm{SiO}_{2}$ substrates. Both deposition and post-annealing parameters were varied in order to find optimal conditions for the formation of single phase $\mathrm{In}_{2} \mathrm{Se}_{3}$. In agreement with the previous report $[1,2]$ it was observed that $\mathrm{Zn}$ doping during deposition promoted formation of $\kappa-\operatorname{In}_{2} \mathrm{Se}_{3}$, while air exposure or passivation layer deposition suppressed it. $\mathrm{Zn}$ doping allows single-phase $\kappa-\mathrm{In}_{2} \mathrm{Se}_{3}$ to be deposited in polycrystalline form onto substrates heated in the 125 to $250^{\circ} \mathrm{C}$ range, while wellannealed undoped films always contained some $\gamma$-phase.[3] The $\kappa-\operatorname{In}_{2} \mathrm{Se}_{3}$ film used in this study was a $500 \mathrm{~nm}$-thick layer deposited at $125^{\circ} \mathrm{C}$ using $\mathrm{Se} / \mathrm{In}$ flux ratio of 1.5 , and then annealed for 30 minutes at $350^{\circ} \mathrm{C}$ in $\mathrm{Ar}$ ambient. The $\mathrm{Zn}$ flux was chosen to give nominal $0.5 \%$ doping, which was confirmed by energy dispersive X-ray (EDX) analysis. A single-phase film of $\gamma-\operatorname{In}_{2} \mathrm{Se}_{3}$ was selected as a reference sample. This $450 \mathrm{~nm}$-thick film was deposited at $400^{\circ} \mathrm{C}$ using $\mathrm{Se} / \mathrm{In}$ flux ratio of 1.64 , and held at $400^{\circ} \mathrm{C}$ for an additional 30 minutes. EDX measurements confirmed the chemical composition of both films showing that within experimental errors (which were smaller than 2\%) In and Se mole fractions were $40 \%$ and $60 \%$, respectively. 
The X-ray diffraction pattern measured for the $\gamma$ - $\operatorname{In}_{2} \mathrm{Se}_{3}$ film is shown in Fig.1 (a). In addition to strong $(00 l)$ peaks the spectrum contains a few weak peaks with mixed indices which indicate that, in addition to grains aligned along the c-axis, there are also some grains with other orientations. The X-ray diffraction spectrum obtained for the $\kappa-$ $\mathrm{In}_{2} \mathrm{Se}_{3}$ film is shown in Fig.1 (b). Using this spectrum the $2 \theta$ angle for the (005) peak was measured to be $22.33^{\circ}$, implying $\mathrm{c}=1.988 \mathrm{~nm}$. This value agrees very well with the measurement of deGroot and Moodera [1].

The X-ray diffraction spectra measured for $\gamma$ - and $\kappa$-phase films show substantial differences. First of all, the spectrum of the $\gamma$-phase film contains only the (006) peak and its higher-order peak (0012), whereas the $\kappa$-phase film exhibits all $(00 l)$ peaks. The appearance of a vacancy-ordered-in-screw-form (VOSF) phase in which all the forbidden (00l) reflections appear has previously been reported in single crystals by Ye et al.[4] and in thin films by Ohtsuka et al.[5] The structure of the VOSF is compared to that of $\kappa-$ $\mathrm{In}_{2} \mathrm{Se}_{3}$ in more detail below.

Unlike the case of the $\gamma$ - or $\alpha$-phases, the $(00 l)$ peaks of $\kappa-\operatorname{In}_{2} \mathrm{Se}_{3}$ which have odd $l$ indexes have stronger intensity than the neighboring $(00 l)$ lines with even $l$ indexes. This confirms de Groot's claim that the odd- $l$ peaks of the $\kappa-\mathrm{In}_{2} \mathrm{Se}_{3}$ are more intense in the Xray diffraction pattern [1]. Such unusual line intensity is a manifestation of some symmetry breaking in $\kappa-\operatorname{In}_{2} \mathrm{Se}_{3}$. The second significant difference between the two diffraction patterns is absolute line intensity; the peak intensity for the $\gamma$-phase is about two orders of magnitude greater than that of the $\kappa$-phase. This is true even for the best $\kappa-$ films, suggesting that the c-axis coherence length is much longer for the $\gamma$-phase films.

Transmission electron microscopy (TEM) was used to investigate the microstructure and crystallographic properties of both films. It showed that both layers 
are polycrystalline but, with considerably different microstructure. In the case of $\gamma-\operatorname{In}_{2} \mathrm{Se}_{3}$, the film grew in a columnar mode. Most grains, which nucleated on the $\mathrm{SiO}_{2}$ substrate, grew primarily along the film normal [see Fig. 2(a)] and are about $0.2 \mu \mathrm{m}$ in size. Only a few of them stopped in the middle of the layer and were overgrown by the neighboring grains. A columnar growth mode resulted in a roughness of about $0.1 \mu \mathrm{m}$. The $\kappa-\mathrm{In}_{2} \mathrm{Se}_{3}$ film does not exhibit a columnar microstructure [see Fig. 2(b)]. Instead, it has a flake-like structure and a flat surface. The grains are relatively thin (0.1-0.2 $\mu \mathrm{m})$, quite wide (typically with a size of a few micrometers) and primarily parallel to the film plane. Only a few small grains with different orientation and a more isotropic shape were observed in the film. The observation that the $\kappa$-phase grains are relatively thin is consistent with the low-intensity, broad X-ray peaks compared to those obtained from the $\gamma$-phase, although some peak broadening may be due the presence of $\mathrm{Zn}$ in the $\kappa$-phase film.

Selected Area Electron Diffraction (SAED) was used to measure the lattice parameters of both films. An application of the smallest selected area aperture (SAA) allowed for obtaining diffraction patterns practically from single grains. Such patterns obtained from cross-sectional specimens are shown in Figs 2(c) and 2(d). For the $\kappa-$ $\mathrm{In}_{2} \mathrm{Se}_{3}$ film the aperture included also a small area of the Si substrate. Therefore the reflections originating from the $\mathrm{In}_{2} \mathrm{Se}_{3}$ are superimposed on those of the $[110]_{\mathrm{Si}}$ diffraction pattern. The Si diffraction spots were used to calibrate the camera constant. In the case of the $\gamma-\operatorname{In}_{2} \mathrm{Se}_{3}$ film, due to the lack of an internal calibration, the same camera constant was applied. From such SAED patterns two inter-planar distances corresponding to two perpendicular crystallographic directions were measured for each film. The following values were obtained: $19.35 \AA$ and $6.15 \AA$ for $\gamma-\operatorname{In}_{2} \mathrm{Se}_{3}$, and $19.85 \AA$ and $7.05 \AA$ for $\kappa-\mathrm{In}_{2} \mathrm{Se}_{3}$. The inter-planar distances obtained for $\gamma-\mathrm{In}_{2} \mathrm{Se}_{3}$ agree, within experimental 
error, with the c-lattice parameter (19.38 $\AA$ [6]) and with the inter-planar distance of the (1100)-type family of planes (6.17 $\AA$ [6]). The larger d-spacing obtained for $\kappa-\mathrm{In}_{2} \mathrm{Se}_{3}$ agrees very well with the value measured from X-ray diffraction. This value is significantly larger than the c-parameter for $\alpha-\operatorname{In}_{2} \mathrm{Se}_{3}(19.235 \AA)$ or twice the c-parameter for $\delta-\operatorname{In}_{2} \mathrm{Se}_{3}(19.28 \AA$ ).[7] The $7.05 \AA$ value, as will be shown later from plan-view study, corresponds to the inter-planar distance of (1100)-type planes, which leads to the a-lattice parameter of $8.14 \pm 0.10 \AA$. Ye et al. determined $\mathrm{a}=7.14 \AA$ and $\mathrm{c}=19.38 \AA$ for their VOSF phase.[4] The smaller c-axis lattice constant of the VOSF shows that it is not the same as $\kappa-\operatorname{In}_{2} \mathrm{Se}_{3}$ and is, as suggested, [4] closer to $\gamma-\operatorname{In}_{2} \mathrm{Se}_{3}$.

SAED study of plan-view specimens prepared from the $\gamma-\operatorname{In}_{2} \mathrm{Se}_{3}$ film showed that many grains had their c-axis aligned closely to the surface normal, as demonstrated by the diffraction ring pattern shown in Fig. 2(e), which was taken using large SAA so many grains contributed to it. Analysis of this pattern shows that well-defined rings (rings formed by a majority of the included grains) are of the ( $h k \underline{h+k} 0)$-type. It means that the majority of the grains have their c-axis aligned along the film normal. However, a more detailed study, with use of small SAA, showed, in agreement with cross-sectional observations [see Fig.1 (a)], that there are also some grains with other orientations, among which the [11ㅡㄹ $\underline{3}$ zone axis was frequently observed. For the $\kappa-\operatorname{In}_{2} \mathrm{Se}_{3}$ the smallest SAA was applied to record the [0001] diffraction pattern from a single grain [Fig. 2(f)]. Due to a lack of internal d-spacing calibration, in order to extract the lattice parameter from this pattern the camera constant, measured from a ring pattern recorder for $\gamma-\operatorname{In}_{2} \mathrm{Se}_{3}$, was used, introducing an error of about 1\%. By consistent indexing of all visible spots using indexes for the [0001] zone axis in the hexagonal system the a-lattice parameter was determined to be $8.03 \pm 0.10 \AA$. This value is in agreement with the one indicated by 
SAED studies of cross-sectional specimens. Consistent though less accurate values of lattice spacing for $\kappa-\mathrm{In}_{2} \mathrm{Se}_{3}$ and $\gamma-\mathrm{In}_{2} \mathrm{Se}_{3}$ films were measured independently from high resolution electron microscopy (HREM) images and their Fourier Transforms (FT) (see Figs 3).

Though little is known about $\kappa-\mathrm{In}_{2} \mathrm{Se}_{3}$, it is believed that this phase must be closely related to $\alpha-\operatorname{In}_{2} \mathrm{Se}_{3} . \alpha-\operatorname{In}_{2} \mathrm{Se}_{3}$ is believed to have a lamellar hexagonal structure [5], while $\gamma$ - $\operatorname{In}_{2} \mathrm{Se}_{3}$ has a defect wurtzite structure, meaning a wurtzite structure with $1 / 3$ of the cation sites vacant.[8,9] The unit cell of the $\gamma-\operatorname{In}_{2} \mathrm{Se}_{3}$ contains six atomic layers. They can be associated with the (0006) planes visible in HREM images obtained from crosssectional samples [see for example Fig. 3(a)]. The $\kappa-\mathrm{In}_{2} \mathrm{Se}_{3}$ phase differs clearly from $\gamma-$ $\operatorname{In}_{2} \mathrm{Se}_{3}$. First, it has the c-lattice parameter significantly increased by about $2.5 \pm 0.2 \%$. The other difference is the number of layers in the unit cell. HREM images obtained from cross-sectional specimens clearly show (0005) planes and they indicate that only five planes are inside the unit cell [see Fig. 3(b)]. However, the composition of these planes and the role and location of vacancies remains unclear.

Our studies also indicate that $\kappa-\operatorname{In}_{2} \mathrm{Se}_{3}$ differs from $\gamma-\mathrm{In}_{2} \mathrm{Se}_{3}$ phase when viewed along the c-axis. Combining value of the a-lattice parameter determined from crosssectional study $(8.14 \pm 0.10 \AA)$ with the one obtained from plan-view $(8.03 \pm 0.10 \AA)$ one can estimate that $\mathrm{a}=8.09 \pm 0.05 \AA$. This means the a-lattice parameter of the $\kappa-\mathrm{In}_{2} \mathrm{Se}_{3}$ is about $13.5 \pm 0.5 \%$ greater than that of the $\gamma$-phase and is approximately, within the error bounds, twice the a-axis lattice parameter of the $\alpha-\mathrm{In}_{2} \mathrm{Se}_{3}$ structure. The symmetry of the unit cell along the c-axis differs from $\gamma-\mathrm{In}_{2} \mathrm{Se}_{3}$ as shown by the SAED study - in the [0001] $\kappa-\mathrm{In}_{2} \mathrm{Se}_{3}$ diffraction pattern all spots with all even indexes have strong intensity [Fig. 2(f)]. On the other hand, calculation of the [0001] SAED pattern of the $\gamma$-phase 
indicates that in case of this phase such a rule applies only to low-index spots. The different symmetry of the two phases is consistent with the atypical peak intensities in the X-ray diffraction spectrum of $\kappa-\operatorname{In}_{2} \mathrm{Se}_{3}$.

In bulk, $\gamma-\operatorname{In}_{2} \mathrm{Se}_{3}$ is believed to be the stable form at room temperature while $\alpha$ phase can be produced by a quench from high temperature.[8] Some authors report that a high Se/In ratio in amorphous multilayers or a high Se overpressure during annealing of amorphous films promote formation of the $\gamma$-phase,[8] while others report that a high Se overpressure during hot depositions results in the $\alpha$-phase.[5] The $\kappa$-phase on the other hand seems to heterogeneously nucleate from the free top surface during annealing of an amorphous film at temperatures too low to nucleate the $\gamma$-phase.[1] Ye and coworkers observe slow conversion of the $\gamma$-phase to the VOSF phase during long anneals, [4] while contrarily long anneals tend to turn $\kappa$-phase material into $\gamma$-phase.[3] Obviously the kinetics of nucleation and transformation of phases in $\mathrm{In}_{2} \mathrm{Se}_{3}$ is very complex.

In conclusion, polycrystalline films of $\gamma-\operatorname{In}_{2} \mathrm{Se}_{3}$ and $\kappa-\mathrm{In}_{2} \mathrm{Se}_{3}$ were studied using different techniques. EDX and X-ray diffraction confirmed the chemical composition and phase uniformity of these films. TEM study revealed that the $\gamma$ - $\operatorname{In}_{2} \mathrm{Se}_{3}$ film had a columnar structure whereas $\kappa-\operatorname{In}_{2} \mathrm{Se}_{3}$ is flake-like. Both the SAED study and the HREM images showed that $\kappa-\mathrm{In}_{2} \mathrm{Se}_{3}$ has a significantly larger unit cell than the $\gamma$-phase. The clattice parameter is increased by about $2.5 \pm 0.2 \%$ and the a-lattice parameter by about $13.5 \pm 0.5 \%$. The experimental results indicate also that not only the size but the structure and the symmetry of the $\kappa-\operatorname{In}_{2} \mathrm{Se}_{3}$ unit cell is generally similar to $\alpha-\operatorname{In}_{2} \mathrm{Se}_{3}$ but different in detail from previously described $\mathrm{In}_{2} \mathrm{Se}_{3}$ phases. Finally, in this work, we were able to obtain the [0001] electron diffraction pattern of $\kappa-\operatorname{In}_{2} \mathrm{Se}_{3}$ and measure the a-lattice parameter of this novel phase. 
The authors would like to thank National Center for Electron Microscopy at LBNL for the opportunity to use its facilities. 


\section{References}

1. C. de Groot and J.S. Moodera, J. Appl. Phys. 89, 4336 (2001).

2. H. Haeuseler and M. Himmrich, Z. anorg. Allg. Chem. 535, 13 (1986).

3. A. Chaiken, K. Nauka, G. Gibson and C.C. Yang, unpublished results.

4. J. Ye, S. Soeda, Y. Nakamura and O. Nittono, Jpn. J. Appl. Phys. 37, 4264 (1998).

5. T. Ohtsuka, K. Nakanishi, T. Okamoto, A. Yamada, M. Konagai and U. Jahn, Jpn. J. Appl. Phys. 40, 509 (2001).

6. H. Lutz et al., J. Less-Common Met., 143, 83 (1988).

7. S. Popovic, A. Tonejc, B. Grzeta-Plenkovic, B. Celustka and R. Trojko, J. Appl. Cryst. 12, 416 (1979).

8. M. Emziane, S. Marsillac and J.C. Bernède, Mat. Chem. Phys. 62, 84 (2000).

9. T. Ohtsuka, T. Okamoto, A. Yamada, and M. Konagai, Jpn. J. Appl. Phys. 38, 4131 (1999). 


\section{Figure Captions}

Fig. 1. X-ray diffraction spectra taken with $\mathrm{Cu} \mathrm{K} \alpha$ radiation for: a) $\gamma$ - $\mathrm{In}_{2} \mathrm{Se}_{3}$ and b) $\kappa$ $\mathrm{In}_{2} \mathrm{Se}_{3}$ films.

Fig. 2. (a) and (b) Bright field cross-sectional TEM micrographs of $\gamma-\operatorname{In}_{2} \mathrm{Se}_{3}$ and $\kappa-\mathrm{In}_{2} \mathrm{Se}_{3}$ films (an amorphous layer between the silicon substrate and the polycrystalline film of $\kappa$ $\mathrm{In}_{2} \mathrm{Se}_{3}$ is an artifact due to TEM specimen preparation). (c) and (d) SAED patterns obtained from cross-sectional specimens prepared from $\gamma-\operatorname{In}_{2} \mathrm{Se}_{3}$ and $\kappa-\mathrm{In}_{2} \mathrm{Se}_{3}$ films. (e) and (f) SAED patterns obtained from plan-view specimens prepared from $\gamma$ - $\operatorname{In}_{2} \mathrm{Se}_{3}$ and $\kappa$ $\mathrm{In}_{2} \mathrm{Se}_{3}$ films. Notice that camera constant for patterns shown in (c) and (d) is different from that for patterns shown in (e) and (f).

Fig. 3. HREM images obtained from: (a) cross-sectional specimen from $\gamma$ - $\operatorname{In}_{2} \mathrm{Se}_{3}$ film, (b) and (c) cross-sectional specimen from $\mathrm{\kappa}-\mathrm{In}_{2} \mathrm{Se}_{3}$ film and (d) plan-view specimen from $\mathrm{\kappa}$ $\mathrm{In}_{2} \mathrm{Se}_{3}$ film. Insets show FTs of these images. 


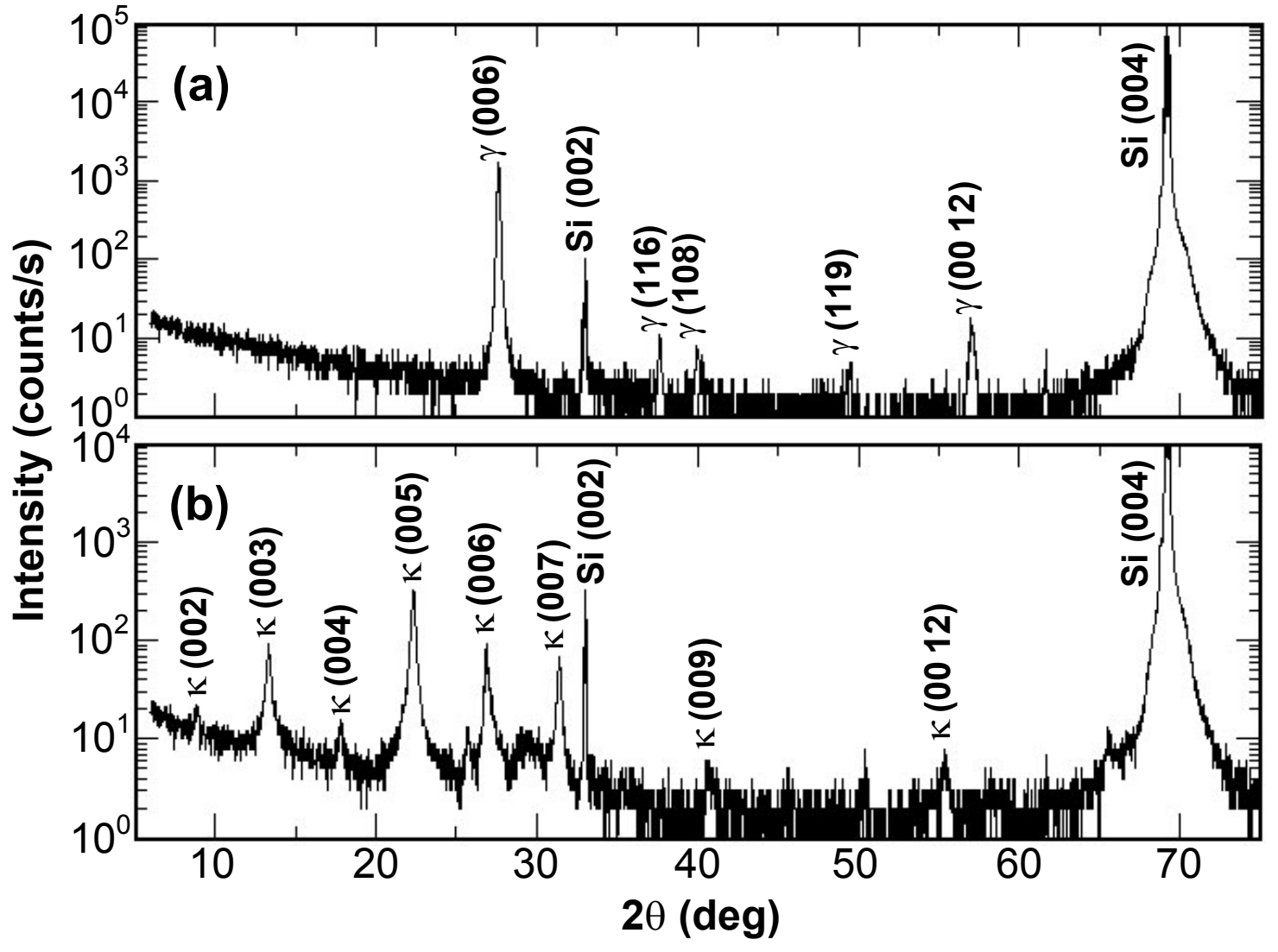

J. Jasinski et al, Ms. \#L02-2774, Fig.1 

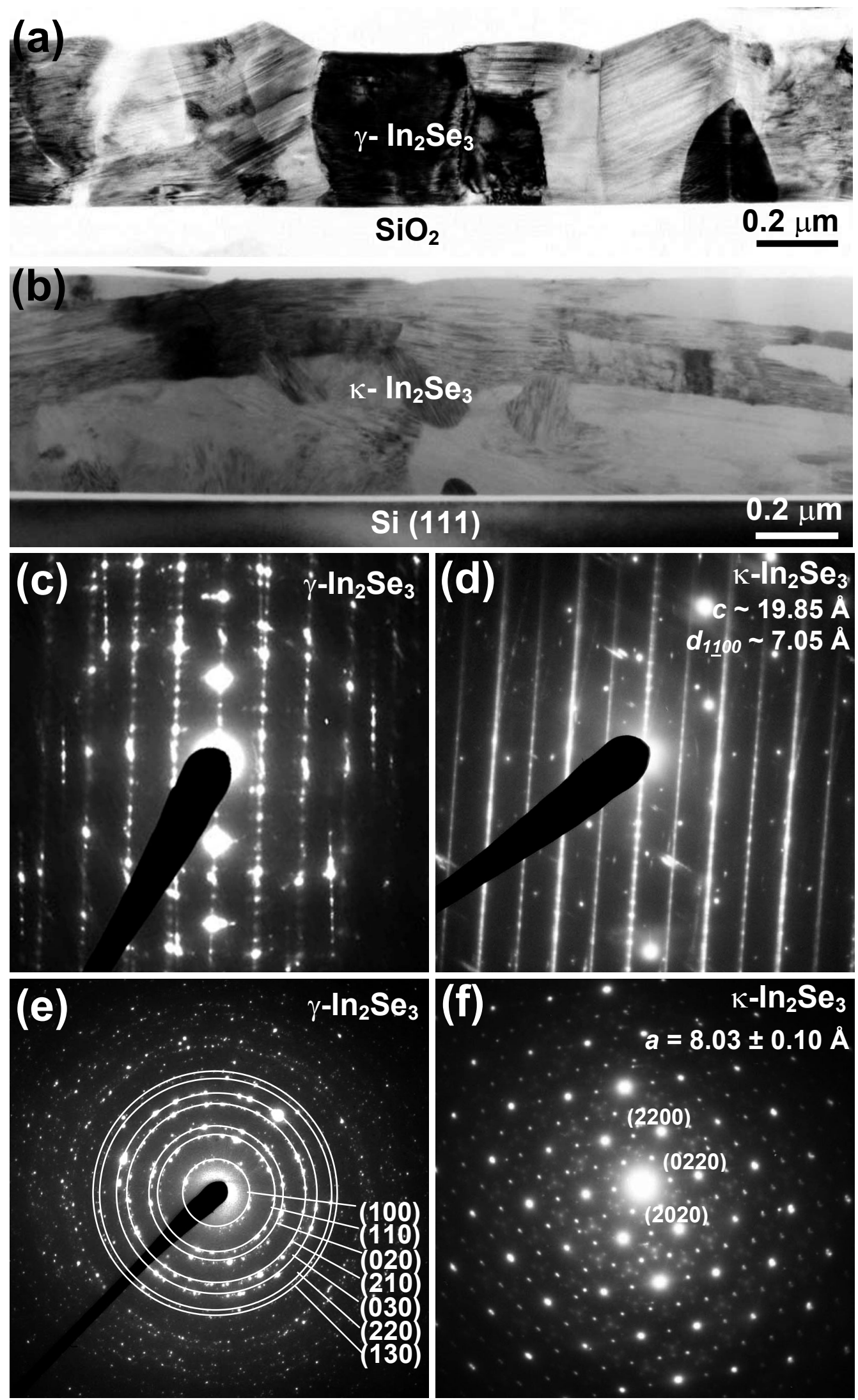

J. Jasinski et al, Ms. \#L02-2774, Fig.2 

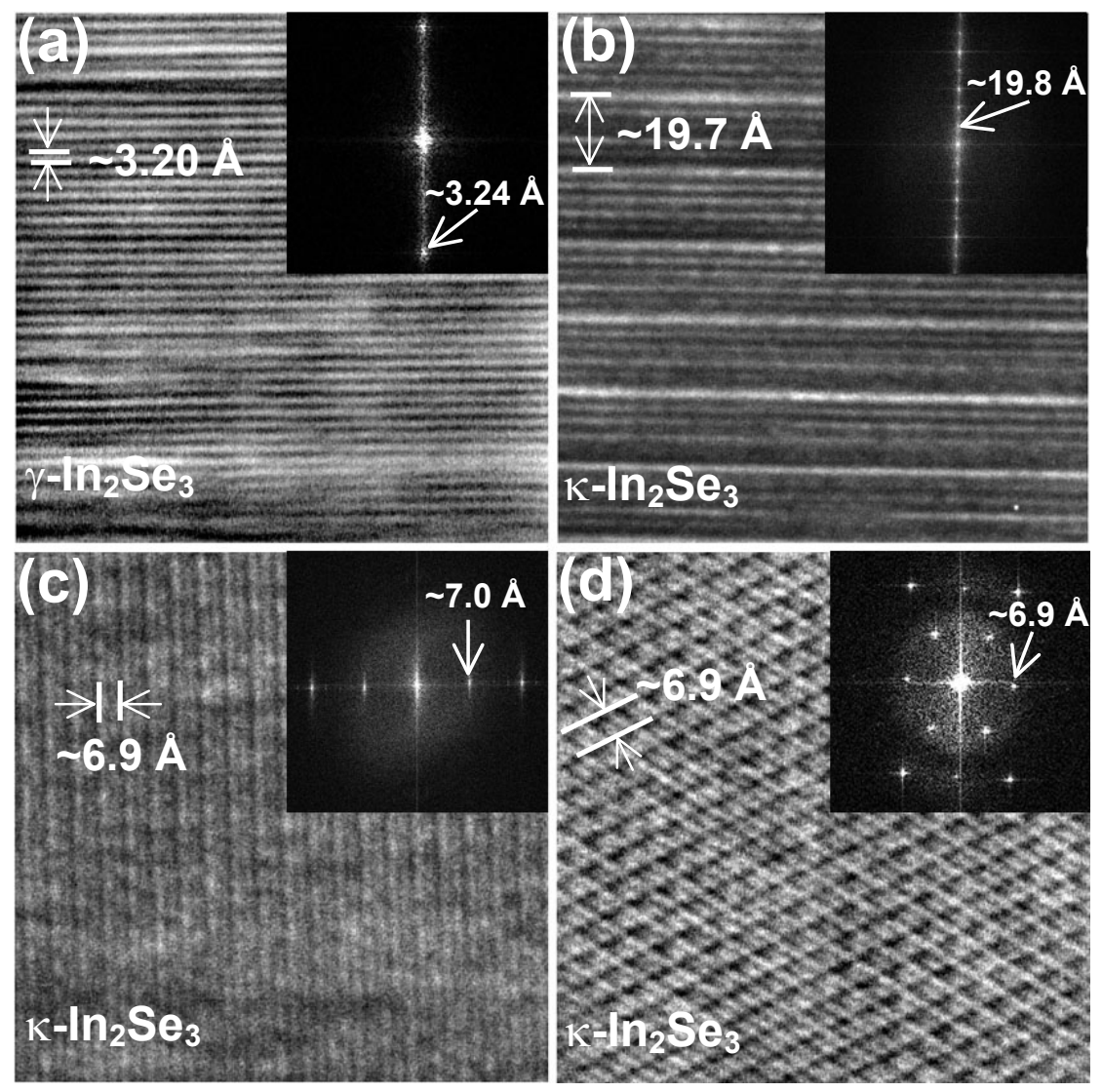

J. Jasinski et al, Ms. \#L02-2774, Fig.3 